International Journal of

Environmental Research and

Public Health

ISSN 1660-4601

Article

www.mdpi.com/journal/ijerph

\title{
Recruitment and Baseline Characteristics of Participants in the Finnish Geriatric Intervention Study to Prevent Cognitive Impairment and Disability (FINGER)—A Randomized Controlled Lifestyle Trial ${ }^{\dagger}$
}

Tiia Ngandu ${ }^{1,2 *}$, Jenni Lehtisalo ${ }^{1}$, Esko Levälahti ${ }^{1}$, Tiina Laatikainen ${ }^{1,3}$, Jaana Lindström ${ }^{1}$, Markku Peltonen ${ }^{1}$, Alina Solomon ${ }^{2,4,5}$, Satu Ahtiluoto ${ }^{1}$, Riitta Antikainen ${ }^{6,7,8}$, Tuomo Hänninen ${ }^{9}$, Antti Jula ${ }^{1}$, Francesca Mangialasche ${ }^{5}$, Teemu Paajanen ${ }^{10}$, Satu Pajala ${ }^{11}$, Rainer Rauramaa ${ }^{12}$, Timo Strandberg ${ }^{6,13}$, Jaakko Tuomilehto ${ }^{14,15,16,17}$, Hilkka Soininen ${ }^{4,9}$ and Miia Kivipelto ${ }^{1,2,4,5}$

1 Department of Chronic Disease Prevention, National Institute for Health and Welfare, P.O. Box 30, FI-00271 Helsinki, Finland; E-Mails: jenni.lehtisalo@thl.fi (J.Le.); esko.levalahti@thl.fi (E.L.); tiina.laatikainen@thl.fi (T.L.); jaana.lindstrom@thl.fi(J.Li.); markku.peltonen@thl.fi (M.P.); satu.ahtiluoto@fimnet.fi (S.A.); antti.jula@thl.fi (A.J.); miia.kivipelto@ki.se (M.K.)

2 Alzheimer's Disease Research Center, Karolinska Institutet, Novum 5th floor, SE-14157 Stockholm, Sweden

3 Institute of Public Health and Clinical Nutrition, University of Eastern Finland, P.O. Box 1627, FI70211 Kuopio, Finland

4 Department of Neurology, Institute of Clinical Medicine, University of Eastern Finland, P.O. Box 1627, FI-70211 Kuopio, Finland; E-Mails: alina.solomon@uef.fi (A.S.); hilkka.soininen@uef.fi (H.S.)

5 Aging Research Center, Karolinska Institutet-Stockholm University, Gävlegatan 16, SE-11330 Stockholm, Sweden; E-Mail: Francesca.Mangialasche@ki.se

6 Institute of Health Sciences/Geriatrics, University of Oulu, and Oulu University Hospital, P.O. Box 5000, FI-90014 University of Oulu, Finland; E-Mails: riitta.antikainen@ouka.fi (R.A.); timo.strandberg@oulu.fi (T.S.)

7 Medical Research Center Oulu, Oulu University Hospital and University of Oulu, P.O. Box 5000, FI-90014 University of Oulu, Finland

8 Oulu City Hospital, Kiviharjuntie 5, FI-90015 Oulu, Finland

9 Department of Neurology, Kuopio University Hospital, P.O. Box 100, FI-70029 KYS, Kuopio, Finland; E-Mail: tuomo.hanninen@kuh.fi

${ }^{10}$ Finnish Institute of Occupational Health, Topeliuksenkatu 41 a A, FI-00250 Helsinki, Finland; E-Mail: teemu.paajanen@ttl.fi 
11 Department of Lifestyle and Participation, National Institute for Health and Welfare, P.O. Box 30, FI-00271 Helsinki, Finland; E-Mail: satu.pajala@thl.fi

12 Kuopio Research Institute of Exercise Medicine, Kuopion yliopisto, Haapaniementie 16, 70100 Kuopio, Finland; E-Mail: rainer.rauramaa@uef.fi

13 Department of Medicine, Geriatric Clinic, University of Helsinki, and Helsinki University Central Hospital, P.O. Box 22, FI-00014 University of Helsinki, Finland

14 Department of Public Health, University of Helsinki, P.O. Box 40, FI-00014 University of Helsinki, Finland; E-Mail: jaakko.tuomilehto@thl.fi

15 South Ostrobothnia Central Hospital, Huhtalantie 53, FI-60220 Seinäjoki, Finland

${ }^{16}$ Center for Vascular Prevention, Danube-University Krems, Dr.-Karl-Dorrek-Str. 30, 3500 Krems, Austria

17 Diabetes Research Group, King Abdulaziz University, P.O. Box 80200, Jeddah 21589, Saudi Arabia

$\dagger$ This paper is an extended version of a work presented at the Alzheimer's Association International Conference, Copenhagen, Denmark, 12-17 July 2014.

* Author to whom correspondence should be addressed; E-Mail: tiia.ngandu@thl.fi;

Tel.: +358-29-524-7716.

Received: 9 July 2014; in revised form: 31 August 2014 / Accepted: 2 September 2014 /

Published: 10 September 2014

Abstract: Our aim is to describe the study recruitment and baseline characteristics of the Finnish Geriatric Intervention Study to Prevent Cognitive Impairment and Disability (FINGER) study population. Potential study participants (age 60-77 years, the dementia risk score $\geq 6$ ) were identified from previous population-based survey cohorts and invited to the screening visit. To be eligible, cognitive performance measured at the screening visit had to be at the mean level or slightly lower than expected for age. Of those invited $(\mathrm{n}=5496), 48 \%(\mathrm{n}=2654)$ attended the screening visit, and finally 1260 eligible participants were randomized to the intervention and control groups (1:1). The screening visit non-attendees were slightly older, less educated, and had more vascular risk factors and diseases present. The mean (SD) age of the randomized participants was 69.4 (4.7) years, Mini-Mental State Examination 26.7 (2.0) points, systolic blood pressure 140.1 (16.2) $\mathrm{mmHg}$, total serum cholesterol 5.2 (1.0) $\mathrm{mmol} / \mathrm{L}$ for, and fasting glucose $6.1(0.9) \mathrm{mmol} / \mathrm{L}$ for, with no difference between intervention and control groups. Several modifiable risk factors were present at baseline indicating an opportunity for the intervention. The FINGER study will provide important information on the effect of lifestyle intervention to prevent cognitive impairment among at risk persons. 
Keywords: cognitive impairment; dementia; Alzheimer's disease; lifestyle; intervention; randomized controlled trial

\section{Introduction}

With the aging population, it has been projected that the number of persons with cognitive impairment and dementia will increase rapidly in the coming years [1]. Longitudinal population-based studies have identified many potentially modifiable vascular, metabolic, and life-style related risk factors for dementia and Alzheimer's disease (AD) [2].

Interventions on modifiable risk factors may prevent/postpone dementia onset, but the pharmacological and non-pharmacological intervention studies conducted so far have had somewhat disappointing results as pointed out in a report by the National Institutes of Health [3]. There are several reasons for this. Previous trials have mostly used a single agent intervention and they have been conducted in older and/or already cognitively impaired populations, which may partly explain the modest results. Many of these trials were planned for other outcomes and cognitive outcomes were secondary. There are however some positive signs that antihypertensive drug treatment [4], vitamin B supplementation [5], physical activity [6] and cognitive training [7] may be beneficial, at least in certain population groups. Given the multifactorial nature of dementia/AD, and the long prodromal period, it has been proposed that the optimal feasible clinical trial should be a multidomain intervention targeting an at-risk population [3]. Such multidomain lifestyle interventions have demonstrated dramatic benefits in the development of type 2 diabetes in high-risk individuals [8].

To interpret the results of the intervention studies and to use the results in developing intervention programs, it is important to understand who participates in these trials, and to what extent the results may be generalizable. Little is known about the determinants of participation in clinical trials among older people, as studies are often conducted at memory clinic settings or among volunteers recruited through advertisements, etc. In one cognitive training trial, participants were younger, more likely to be female, and had higher education than the general population of the same age-range [9]. Often these demographic data are the only data available for comparison. In some previous observational studies it has been reported that the non-participants had lower cognitive test performance [10] and higher prevalence of dementia [11]. There are few health promotion and physical activity trials among older adults, however not focusing on $\mathrm{AD}$ or cognition, with varying reports on non-participation: the participants have reported more health problems [12] than the non-participants in one study, but better health in another [13]. One study reported that while those non-participants who refused to participate were healthier, those who could not be reached were less healthy than the participants [14].

We have initiated the Finnish Geriatric Intervention Study to Prevent Cognitive Impairment and Disability (FINGER) [15] to investigate whether a multidomain intervention could prevent cognitive decline and eventually dementia. It is a 2-year randomized controlled trial (RCT) targeting several known risk factors simultaneously through an intervention consisting of nutritional guidance, exercise training, cognitive training, and intensive monitoring of vascular risk factors. The participants were recruited from earlier population-based cardiovascular disease and type 2 diabetes (non-intervention) 
surveys, which gives us unique background information on both participants and those that did not participate. This is rarely available in clinical trials. The aim of this report is two-fold: first we will describe the demographic, medical and lifestyle characteristics of screening visit attendees and nonattendees. Second, we will describe the recruitment process and baseline characteristics and cognitive assessments of the study participants in the intervention and control groups.

\section{Experimental Section}

The protocol of the FINGER study (ClinicalTrials.gov identifier: NCT01041989) has been described earlier [15]. In brief, the FINGER study is an ongoing multi-centre randomized controlled trial. The 2-year multidomain intervention consists of nutritional guidance; exercise; cognitive training and social activity; and management of metabolic and vascular risk factors. Persons in the control group receive regular health advice. The primary outcome is cognitive performance measured with the modified Neuropsychological Test Battery (mNTB). Main secondary outcomes are: dementia (after extended follow-up), disability, vascular risk factors and outcomes, depressive symptoms, quality of life, and neuroimaging measures. The intensive intervention was completed in 2014, and the participants are followed-up for additional five years. The FINGER study has been approved by the Coordinating Ethics Committee of the Helsinki and Uusimaa Hospital District. The participants gave written informed consent at the time of both the screening and baseline visits.

\subsection{Recruitment}

The participants were recruited from persons who had earlier participated in population-based non-communicable disease risk factor surveys: the National FINRISK study [16] in 1972, 1977, 1982, 1987, 1992, 1997, 2002 or 2007, or the Finnish type 2 diabetes prevention program's population survey [17] in 2004 or 2007. These independent cross-sectional surveys were conducted for health surveillance purposes to monitor chronic disease risk factor levels in the population. The participation rates of these surveys were good, ranging from $70 \%$ to above $96 \%$ in the birth cohort that was the target of the FINGER study $[16,18]$. The recruitment of participants was started from the most recent survey, and moved on to earlier surveys when all eligible persons of the most recent survey had been invited.

To be invited, the person had to be aged 60-77 years (born between 1 January 1932 and 31 December 1949) at the beginning of the study, and have Cardiovascular Risk Factors, Aging and Incidence of Dementia (CAIDE) Dementia Risk Score [19] of 6 points or higher, and be alive when the sample was drawn in May 2009. The score includes easily measurable variables (age, sex, education, hypertension, hypercholesterolemia, obesity and physical inactivity) that are associated with the risk of dementia. The 6 points cut-off is relatively low but indicates a presence of some modifiable risk factors. The majority (84\%) of our source population met this criterion, excluding only those with very low risk of dementia. At the screening visit participants' cognition was assessed with The Consortium to Establish a Registry for Alzheimer's Disease (CERAD) neuropsychological battery [20]. To be included in the FINGER, the participants had to fulfil at least one of the following criteria: (1) Word List Learning task (10 words $\times 3$ ) $\leq 19$ words; or (2) Word List Recall $\leq 75 \%$; or (3) Mini Mental State Examination (MMSE) $\leq 26 / 30$ points. This criteria selects persons with cognitive 
performance at the mean level or slightly lower than expected for age according to Finnish population norms (inclusion cut-off $z$-scores $-0.5,-0.2$ and -0.9 respectively) [21]. Theoretical formation of this at-risk population is presented in Figure 1. Exclusion criteria were conditions affecting engagement in the intervention (especially the exercise component): present malignant diseases, major depression, dementia/substantial cognitive decline according to clinical interview, MMSE $<20$, symptomatic cardiovascular disease, re-vascularisation within one year, severe loss of vision, hearing or communicative ability, conditions preventing co-operation as judged by the local study physician, as well as coincident participation in any other intervention trial.

Figure 1. FINGER inclusion criteria and target population.

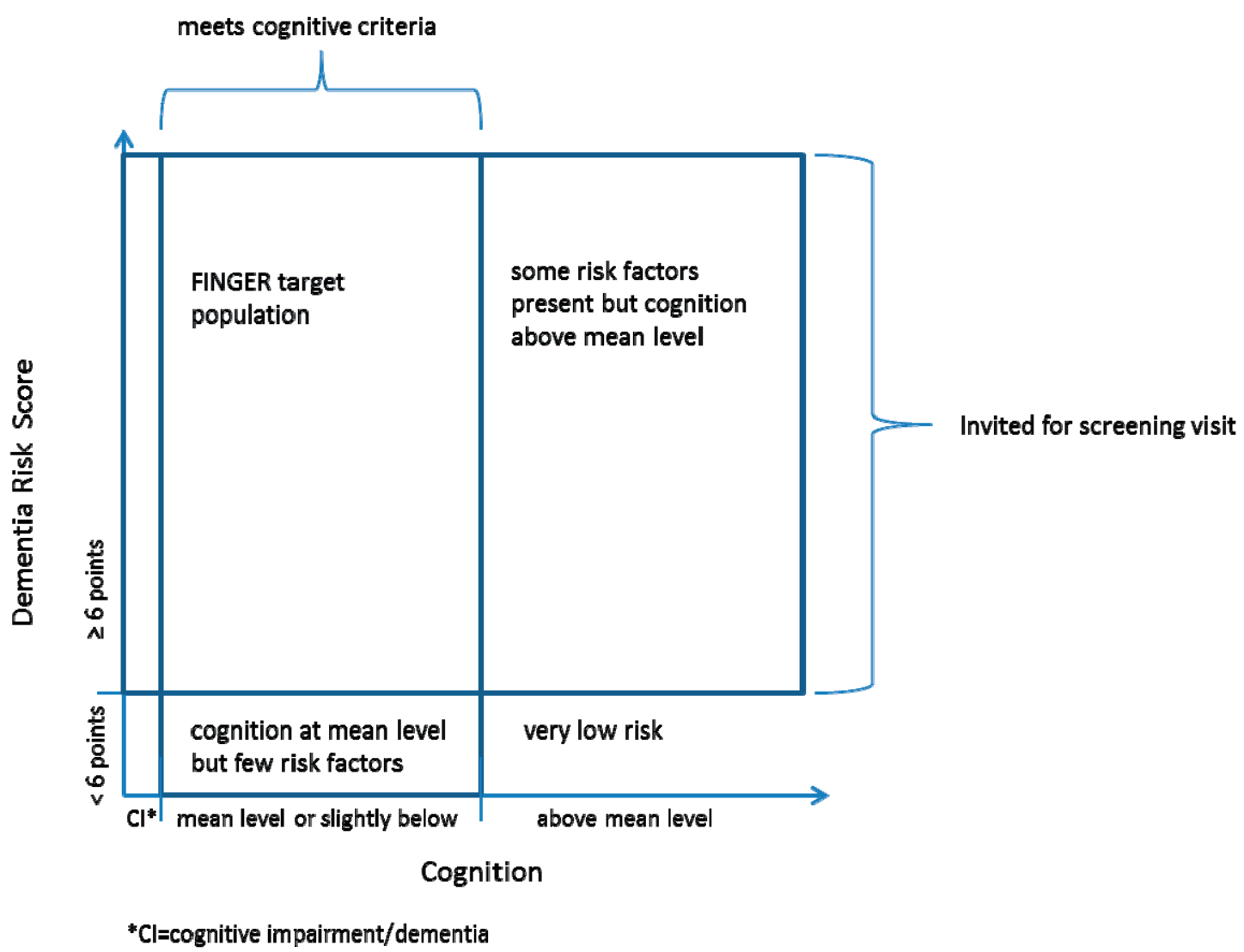

Screening began in September 2009 in the five original study areas in Finland (in and around the cities of Helsinki, Kuopio, Oulu, Seinäjoki, Vantaa), and a sixth area (Turku) was added in April 2010 to ensure sufficient recruitment in a reasonable time frame. Screening was completed in December 2011 when the intended recruitment target $(n=1200)$ was achieved.

After completing the baseline measurements randomization was performed in blocks of four persons (two persons randomly allocated to each group) at each site by the study nurse running a computer program. If spouses participated in the trial, the randomization status of the latter recruited spouse was manually changed to match the randomization of the first recruited spouse.

\subsection{Measurements}

The baseline study visit comprised of a detailed medical history and physical examination by trained study physicians, and measurements of height (without shoes), weight (in light indoor 
clothing), waist (midway between the lowest rib and iliac crest) and hip (at the point yielding the maximum circumference over the buttocks) circumference in a standing position, and systolic and diastolic blood pressure (two measurements using a validated automatic device (Microlife WatchBP Office) in a sitting position, using the right arm, after 10 min of rest) by trained study nurses. Mean value of two blood pressure measurements was used. A fasting venous blood sample was taken from all participants, and a $2 \mathrm{~h}$ oral glucose tolerance test with a $75 \mathrm{~g}$ glucose load was done in the participants without history of diabetes. Fluoride citrate tubes were used for glucose samples. The separated serum and plasma samples were frozen immediately and mailed monthly to the laboratory of the National Institute for Health and Welfare. Total serum cholesterol and plasma glucose concentrations were determined enzymatically using commercial reagents from Abbott Laboratories on a clinical chemistry analyzer, Architect c8000 (Abbott Laboratories, Abbott Park, IL, USA). The participants filled structured questionnaires including questions of sociodemographic factors, health status, lifestyles, mood and quality of life. The Short Physical Performance Battery [22] was administered by trained physiotherapists.

A thorough cognitive assessment using a set of standard neuropsychological tests (an extended and adapted version of the NTB [23]) was administered by trained study psychologists. The primary outcome measure is the total composite mNTB score including 14 tests that form three different cognitive domains. The memory domain included Visual Paired Associates immediate (score range, 018) and delayed (score range, 0-6); Logical Memory immediate (score range, 0-25) and delayed (score range, 0-25) of the Wechsler Memory Scale-Revised (WMS-R) [24]; and Word List Learning (score range, 0-30) and Delayed Recall (score range, 0-10) of the CERAD test battery [20]. The executive function domain included Category Fluency Test [20], Digit Span [24], Concept Shifting Test [25] (condition C), Trail Making Test [26] (shifting score B-A), and a shortened 40-stimulus version of the original Stroop test [27] (interference score 3-2). The processing speed domain included Letter Digit Substitution Test [28], Concept Shifting Test (condition A), and Stroop test (condition 2). All baseline information was collected before randomization.

In addition to the measurements carried out during the screening and baseline visits, we have background information on vascular risk factors and lifestyles available from the earlier background surveys. Data on health status were also collected through computerized register linkage to three nationwide health registers: the Hospital Discharge Register, the National Social Insurance Institution's Drug Reimbursement Registry, and the Causes of Death registry using the national personal identification number. Data on all patients discharged from all hospitals in Finland have been recorded in a computerized Hospital Discharge Register since 1968. The diagnoses for hospitalizations have been coded according to the International Classification of Diseases (ICD) version 8 during 1968 to 1986 , version 9 during 1987 to 1995 , and version 10 since 1996 . We used data on hospitalisations before the onset of study for myocardial infarction (ICD 8 and 9 diagnoses 410 and ICD-10 diagnoses I21-I22), stroke (ICD 8 diagnoses 430, 431 (except 43101, 43191) 433, 434, 436, ICD 9 diagnoses 430, 431, 4330A, 4331A, 4339A, 4340A, 4341A, 4349A, 436 and ICD 10 diagnoses I60-I64 (not I636)), cancer (ICD 8 and 9 diagnoses 140-172, 174-208 and ICD 10 diagnoses C00-C43, C45-C97), diabetes (ICD 8 and 9 diagnoses 250 and ICD 10 diagnoses E10-E14), and dementia (ICD 8 diagnosis 290 ICD 9 diagnoses 290, 3310, 4378A and ICD 10 diagnoses F00, F01, F02, F03, G30). In the register the diagnoses are assigned by the physician treating the patient. The Social Insurance 
Institution's register (reimbursement of pharmaceutical expenses) was used for diabetes (purchases of drugs in Anatomical Therapeutic Chemical (ATC) category A10 or with the Institution's special reimbursement code for diabetes) and dementia (purchases of drugs in ATC category N06D or with special reimbursement code for dementia). Currently the data from all of these registers is available until end of 2011.

\subsection{Statistical Analyses}

The differences between screening visit attendees and non-attendees, between randomized and not-randomized participants, and between intervention and control groups were analysed using chi square-test and $t$-test as appropriate. The level of significance was $5 \%$ in all analyses.

\section{Results and Discussion}

\subsection{Characteristics of the Persons invited to the FINGER Study}

A total of 5496 persons were invited and 2654 (48\% of those invited) attended the screening visit. The screening attendance rates between study sites varied from $43 \%$ to $57 \%$. Compared with the attendees, those who did not attend the screening visit were older, and based on the data from the earlier studies they had participated in, they were more likely to be less educated, and have more vascular and lifestyle risk factors (Table 1). The screening visit non-attendees also had more vascular diseases, diabetes, cancer and dementia as identified through the registries. Mortality between 22 May 2009 when the study population was identified and the 31 December 2011 (data currently available through registers) was higher among those who did not attend the screening visit. Therefore, it is likely that many non-responding persons would have been excluded based on our exclusion criteria, had they attended the screening visit.

Table 1. Background characteristics from earlier surveys and health registries of the persons who were invited to attend the FINGER study screening visit (mean (SD) or \%).

\begin{tabular}{|c|c|c|c|c|}
\hline Characteristic & $\begin{array}{l}\text { All Invited } \\
\mathrm{n}=\mathbf{5 4 9 6}\end{array}$ & $\begin{array}{l}\text { Screened } \\
n=2654\end{array}$ & $\begin{array}{l}\text { Screening Visit } \\
\text { Non-Attendees } \\
\mathbf{n}=\mathbf{2 8 4 2}\end{array}$ & $p$-Value * \\
\hline Age at the beginning of the study $(07.09 .2009)$ & $68.1(5.0)$ & $67.8(4.8)$ & $68.3(5.2)$ & 0.002 \\
\hline Sex $(\%$ men/women $)$ & $50.3 / 49.7$ & $48.8 / 51.2$ & $51.7 / 48.3$ & 0.037 \\
\hline \multicolumn{5}{|l|}{ Study site: } \\
\hline Helsinki (n, \%) & 743 & $389(52.3 \%)$ & $354(47.6 \%)$ & \multirow[t]{6}{*}{$<0.001$} \\
\hline Kuopio (n, \%) & 1444 & $625(43.3 \%)$ & $819(56.7 \%)$ & \\
\hline Oulu (n, \%) & 420 & $240(57.1 \%)$ & $180(42.9 \%)$ & \\
\hline Seinäjoki (n, \%) & 587 & $326(55.5 \%)$ & $261(44.5 \%)$ & \\
\hline Turku (n, \%) & 1400 & $656(46.9 \%)$ & $744(53.1 \%)$ & \\
\hline Vantaa (n, \%) & 902 & $418(46.3 \%)$ & $484(53.7 \%)$ & \\
\hline \multicolumn{5}{|c|}{ Demographic and vascular risk factors from the earlier non-intervention survey } \\
\hline Time between earlier survey and invitation (years) & $14.3(10.0)$ & $12.6(9.7)$ & $15.9(10.1)$ & $<0.001$ \\
\hline Education (years) & $10.4(3.6)$ & $10.7(3.8)$ & $10.0(3.5)$ & $<0.001$ \\
\hline Systolic blood pressure $(\mathrm{mmHg})$ & $143(18.9)$ & $142(18.7)$ & $144(19.1)$ & $<0.001$ \\
\hline Total cholesterol $(\mathrm{mmol} / \mathrm{L})$ & $5.9(1.1)$ & $5.8(1.1)$ & $6.0(1.1)$ & $<0.001$ \\
\hline Body mass index $\left(\mathrm{kg} / \mathrm{m}^{2}\right)$ & $27.7(4.6)$ & $27.7(4.5)$ & $27.7(4.7)$ & 0.575 \\
\hline Physical activity at least 2 times/ week (\%) & $49.9 \%$ & 52.4 & 47.5 & $<0.001$ \\
\hline Dementia risk score (points) & $8.4(1.8)$ & $8.1(1.7)$ & $8.6(1.8)$ & $<0.001$ \\
\hline
\end{tabular}


Table 1. Cont.

\begin{tabular}{|c|c|c|c|c|}
\hline Characteristic & $\begin{array}{l}\text { All Invited } \\
\mathbf{n}=\mathbf{5 4 9 6}\end{array}$ & $\begin{array}{l}\text { Screened } \\
n=2654\end{array}$ & $\begin{array}{l}\text { Screening Visit } \\
\text { Non-Attendees } \\
\mathbf{n}=\mathbf{2 8 4 2}\end{array}$ & $p$-Value * \\
\hline \multicolumn{5}{|l|}{ History of diseases from registers } \\
\hline Myocardial infarction (\%) & 4.1 & 3.5 & 4.6 & 0.032 \\
\hline Stroke $(\%)$ & 4.5 & 3.0 & 5.8 & $<0.001$ \\
\hline Diabetes $(\%)$ & 11.0 & 8.9 & 12.9 & $<0.001$ \\
\hline Cancer $(\%)$ & 8.7 & 7.0 & 10.3 & $<0.001$ \\
\hline Dementia (\%) & 1.1 & 0.3 & 2.0 & $<0.001$ \\
\hline Mortality between May 2009 and 31 Dec 2011 (\%) & 3.2 & 0.8 & 5.4 & $<0.001$ \\
\hline
\end{tabular}

* The $p$ value refers to difference between screening visit attendees and non-attendees.

Figure 2. Formation of the study population.

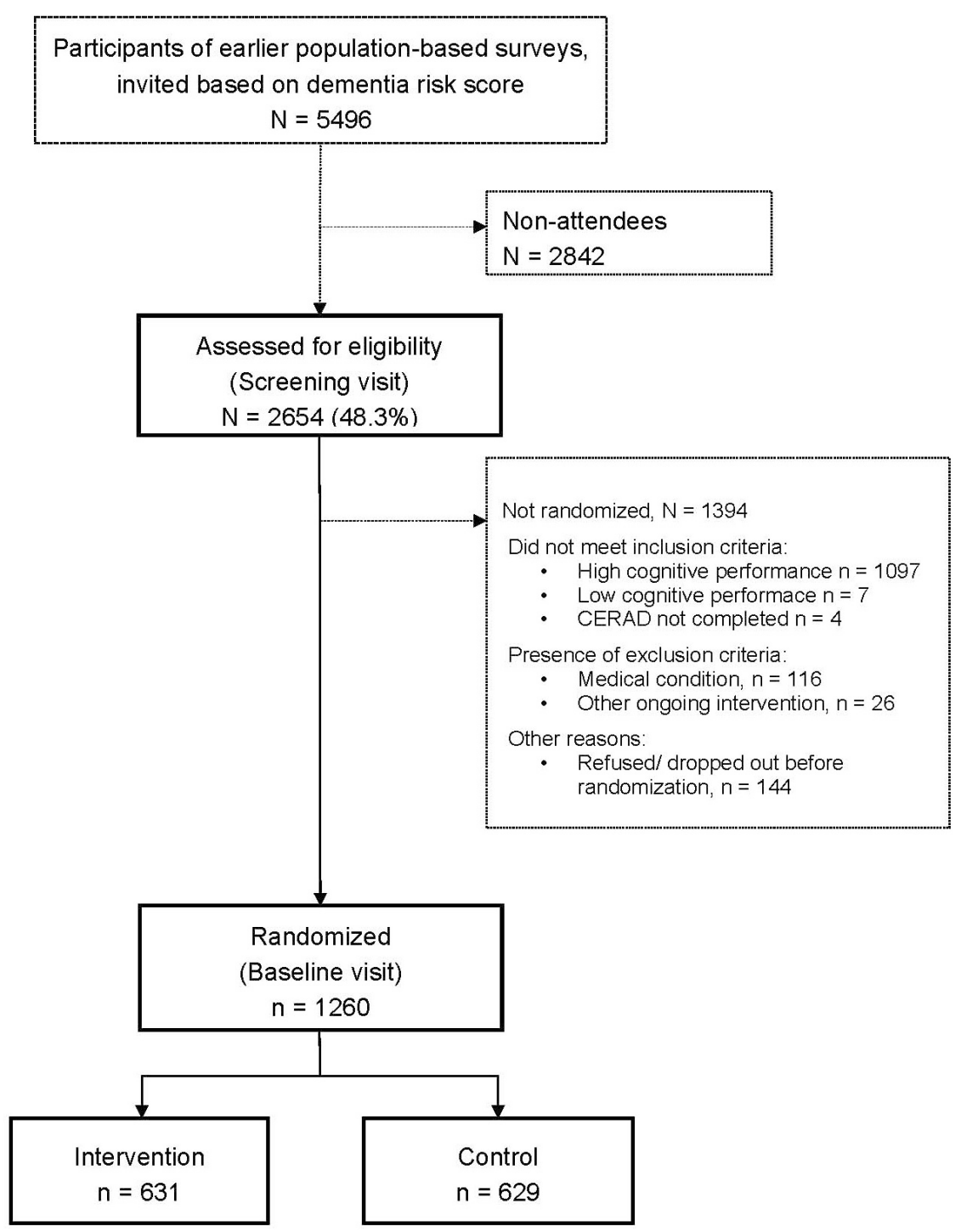

Nearly half of the persons who attended the screening visit fulfilled the cognition criteria for inclusion (Figure 2). The majority of persons who were not included based on their cognitive performance had too high scores, and only seven persons were not included because of too low MMSE score. A total of 142 persons were excluded due to other reasons (too ill including persons suspected to have significant cognitive impairment, participation in another ongoing intervention trial). 
Additionally 144 persons dropped out after the screening visit but before randomization. This left us with 1260 participants randomized into an intensive multidomain intervention group (intervention, $\mathrm{n}=631$ ) and a regular health advice group (control, $\mathrm{n}=629$ ).

\subsection{Randomized vs. not Randomized Persons}

The persons who attended the screening visit but who were not randomized were younger, and had higher education, and were less often physically active (based on the data from the background surveys) compared with those who were randomized (Table 2). Blood pressure and serum cholesterol levels were similar in both groups at the time of earlier surveys. Slightly more women than men attended the screening visit but more men than women were eventually randomized. At most study sites, about half of the screened persons were randomized, however, in Turku $36 \%$ and Oulu $42 \%$ of the screened persons were randomized. As expected, based on the inclusion criteria, cognitive test scores were higher among those that did not fulfil the inclusion criteria.

Table 2. Characteristics of the persons who attended the screening visit according to eligibility to the trial (mean (SD) or \%).

\begin{tabular}{|c|c|c|c|}
\hline Characteristic & $\begin{array}{l}\text { Randomized } \\
\mathrm{n}=1260\end{array}$ & $\begin{array}{l}\text { Not Randomized } \\
\mathrm{n}=1394\end{array}$ & $p$-Value \\
\hline Age at the screening visit (years) & $69.2(4.7)$ & $68.3(4.9)$ & $<0.001$ \\
\hline Sex (\% men/women $)$ & $53.3 / 46.7 \%$ & $44.8 / 55.2 \%$ & $<0.001$ \\
\hline \multicolumn{4}{|l|}{ Study site: } \\
\hline Helsinki $(\mathrm{n}=389)$ & 53.5 & 46.5 & \multirow[t]{6}{*}{$<0.001$} \\
\hline Kuopio $(\mathrm{n}=625)$ & 55.2 & 44.8 & \\
\hline Oulu $(\mathrm{n}=240)$ & 41.7 & 58.3 & \\
\hline Seinäjoki (n = 326) & 49.7 & 50.3 & \\
\hline Turku $(\mathrm{n}=656)$ & 36.4 & 63.6 & \\
\hline Vantaa $(n=418)$ & 49.3 & 50.7 & \\
\hline \multicolumn{4}{|c|}{ Demographic and vascular risk factors from the earlier non-intervention survey } \\
\hline Time between earlier survey and invitation (years) & $13.1(10.1)$ & $12.0(9.2)$ & 0.003 \\
\hline Education (years) & $10.0(3.3)$ & $11.4(4.0)$ & $<0.001$ \\
\hline Systolic blood pressure (mmHg) & $141.8(18.8)$ & $142.2(18.5)$ & 0.599 \\
\hline Total cholesterol (mmol/L) & $5.8(1.1)$ & $5.8(1.1)$ & 0.196 \\
\hline Body mass index $\left(\mathrm{kg} / \mathrm{m}^{2}\right)$ & $27.6(4.4)$ & $27.9(4.6)$ & 0.062 \\
\hline Physical activity at least 2 times/ week (\%) & 54.6 & 50.4 & 0.032 \\
\hline Dementia Risk Score (points) & $8.3(1.8)$ & $8.0(1.6)$ & $<0.001$ \\
\hline \multicolumn{4}{|c|}{ Vascular risk factors and cognitive performance at the FINGER screening visit } \\
\hline Systolic blood pressure $(\mathrm{mmHg})$ & $143.4(18.2)$ & $142.8(17.7)$ & 0.413 \\
\hline Diastolic blood pressure (mmHg) & $81.8(10.1)$ & $81.9(10.2)$ & 0.808 \\
\hline Body mass index $\left(\mathrm{kg} / \mathrm{m}^{2}\right)$ & $28.4(6.2)$ & $28.8(9.4)$ & 0.189 \\
\hline Mini Mental State Examination (points) & $26.7(2.0)$ & $28.0(1.9)$ & $<0.001$ \\
\hline CERAD Word List Learning (words) & $18.4(3.2)$ & $21.9(3.5)$ & $<0.001$ \\
\hline CERAD Word Recall (words) & $5.5(1.7)$ & $7.5(1.8)$ & $<0.001$ \\
\hline CERAD Category Fluency (words) & $21.6(5.7)$ & $23.7(6.4)$ & $<0.001$ \\
\hline
\end{tabular}

CERAD: Consortium to Establish a Registry for Alzheimer's Disease.

A majority of not randomized persons were not eligible due to high cognitive performance at the screening visit $(n=1097)$. Those who were not randomized due to other reasons $(n=297)$ were older 
and had lower cognitive performance at the screening visit than the randomized participants, but their vascular characteristics in earlier surveys and at the screening visit did not differ (results not shown).

\subsection{Randomization into Intervention vs. Control Group}

There were no significant differences in sociodemographic, vascular, or lifestyle characteristics between the persons randomized into the intervention and control groups (Table 3). Overall, several vascular risk factors and unhealthy lifestyle factors were present. Nearly $66 \%$ of the participants reported history of hypertension and 67\% hypercholesterolemia, and 50\% had elevated systolic blood pressure and 54\% had elevated serum total cholesterol values at the baseline visit. Approximately 30\% of the participants were obese, and $71 \%$ were engaged in physical activity at least 2 times per week.

Table 3. Baseline characteristics of the persons who were randomized to the trial (mean (SD) or \%).

\begin{tabular}{|c|c|c|c|c|c|}
\hline Characteristics at Baseline & $\mathbf{n}$ & $\begin{array}{l}\text { All } \\
n=1260\end{array}$ & $\begin{array}{l}\text { Intervention } \\
n=631\end{array}$ & $\begin{array}{l}\text { Control } \\
n=629\end{array}$ & $p$-Value \\
\hline \multicolumn{6}{|l|}{ Demographic characteristics } \\
\hline Age at the baseline visit (years) & 1260 & $69.4(4.7)$ & $69.5(4.7)$ & $69.2(4.7)$ & 0.27 \\
\hline Sex (men/women, \%) & 1260 & $53.3 / 46.7$ & $54.7 / 45.3$ & $52.0 / 48.0$ & 0.34 \\
\hline Education (years) & 1244 & $10.0(3.4)$ & $10.0(3.5)$ & $10.0(3.4)$ & 0.91 \\
\hline Married/ cohabiting $(\%)$ & 1259 & 74.3 & 73.0 & 75.5 & 0.31 \\
\hline \multicolumn{6}{|l|}{ Vascular factors } \\
\hline Systolic blood pressure (mmHg) & 1249 & $140.1(16.2)$ & $140.2(16.7)$ & $140.0(15.7)$ & 0.75 \\
\hline Systolic blood pressure $>140 \mathrm{mmHg}$ & 1249 & 50.3 & 50.6 & 50.0 & 0.84 \\
\hline Diastolic blood pressure (mmHg) & 1249 & $80.3(9.5)$ & $80.5(9.6)$ & $80.1(9.3)$ & 0.48 \\
\hline Diastolic blood pressure $>90 \mathrm{mmHg}$ & 1249 & 15.0 & 15.9 & 14.0 & 0.33 \\
\hline Serum total cholesterol $(\mathrm{mmol} / \mathrm{L})$ & 1255 & $5.2(1.0)$ & $5.2(1.0)$ & $5.2(1.0)$ & 0.93 \\
\hline Serum total cholesterol $>5.0 \mathrm{mmol} / \mathrm{L}$ & 1255 & 53.7 & 53.8 & 53.6 & 0.94 \\
\hline Fasting plasma glucose $(\mathrm{mmol} / \mathrm{L})$ & 1257 & $6.1(0.9)$ & $6.1(0.8)$ & $6.1(1.0)$ & 0.99 \\
\hline Fasting plasma glucose $>7.0 \mathrm{mmol} / \mathrm{L}$ & 1257 & 10.5 & 10.5 & 10.5 & 0.98 \\
\hline $2 \mathrm{~h}$ oral glucose tolerance test $(\mathrm{mmol} / \mathrm{L})$ & 1085 & $7.0(2.2)$ & $7.0(2.2)$ & $7.0(2.2)$ & 0.95 \\
\hline $2 \mathrm{~h}$ oral glucose tolerance test $>11.0 \mathrm{mmol} / \mathrm{L}$ & 1085 & 5.6 & 5.7 & 5.5 & 0.90 \\
\hline Body mass index $\left(\mathrm{kg} / \mathrm{m}^{2}\right)$ & 1249 & $28.2(4.7)$ & $28.3(4.5)$ & $28.1(4.9)$ & 0.46 \\
\hline Body mass index $>30 \mathrm{~kg} / \mathrm{m}^{2}$ & 1249 & 29.9 & 29.8 & 29.9 & 0.98 \\
\hline Waist circumference $(\mathrm{cm})$ & 1250 & $98.3(12.6)$ & $98.7(12.2)$ & $97.9(13.1)$ & 0.28 \\
\hline \multicolumn{6}{|l|}{ Lifestyles } \\
\hline Physical activity at least 2 times/ week (\%) & 1238 & 71.0 & 70.0 & 72.0 & 0.46 \\
\hline Current smokers $(\%)$ & 1214 & 9.4 & 10.5 & 8.3 & 0.17 \\
\hline Alcohol drinking at least once/week (\%) & 1250 & 51.4 & 51.5 & 51.2 & 0.91 \\
\hline Fish intake at least twice/week (\%) & 1250 & 52.3 & 53.2 & 51.4 & 0.54 \\
\hline Daily intake of vegetables (\%) & 1252 & 61.9 & 61.5 & 62.3 & 0.77 \\
\hline \multicolumn{6}{|l|}{ Self-reported medical conditions } \\
\hline Hypertension (\%) & 1246 & 65.9 & 66.7 & 65.1 & 0.54 \\
\hline Hypercholesterolemia (\%) & 1250 & 67.2 & 65.4 & 69.0 & 0.17 \\
\hline Diabetes $(\%)$ & 1250 & 13.1 & 13.7 & 12.5 & 0.52 \\
\hline History of myocardial infarction (\%) & 1254 & 5.1 & 5.2 & 5.0 & 0.82 \\
\hline History of stroke (\%) & 1251 & 5.4 & 5.3 & 5.6 & 0.79 \\
\hline \multicolumn{6}{|l|}{ Other } \\
\hline Dementia risk score & 1260 & $8.3(1.8)$ & $8.3(1.8)$ & $8.3(1.8)$ & 0.92 \\
\hline Short Physical Performance Battery score & 1178 & $10.8(1.5)$ & $10.8(1.5)$ & $10.8(1.5)$ & 0.96 \\
\hline
\end{tabular}


The mean MMSE score was 26.7 (SD 2.0), and it was similar in the intervention and control groups. There were no statistically significant differences on the individual sub-items of the main outcome variable mNTB between the intervention and control groups at baseline (Table 4). On average $77 \%$ (SD 22) of the items were remembered on the CERAD word recall test (delayed recall/immediate recall of 3rd list).

Table 4. Cognitive performance of the randomized participants and formation of the cognitive outcome modified Neuropsychological Test Battery (mean (SD)).

\begin{tabular}{|c|c|c|c|c|c|}
\hline Characteristics at Baseline & $\mathbf{n}$ & $\begin{array}{l}\text { All } \\
\mathrm{n}=\mathbf{1 2 6 0}\end{array}$ & $\begin{array}{l}\text { Intervention } \\
\mathbf{n}=\mathbf{6 3 1}\end{array}$ & $\begin{array}{l}\text { Control } \\
\mathrm{n}=629\end{array}$ & $p$-Value \\
\hline \multicolumn{6}{|l|}{ Memory } \\
\hline WMS-R Logical Memory (immediate) & 1258 & $11.0(3.7)$ & $10.9(3.8)$ & $11.1(3.6)$ & 0.37 \\
\hline WMS-R Logical Memory (delayed) & 1257 & $9.3(3.9)$ & $9.2(4.0)$ & $9.5(3.8)$ & 0.17 \\
\hline CERAD Word List Learning & 1257 & $18.4(3.2)$ & $18.3(3.2)$ & $18.6(3.3)$ & 0.08 \\
\hline CERAD Word List Recall & 1255 & $5.5(1.7)$ & $5.5(1.7)$ & $5.6(1.7)$ & 0.46 \\
\hline WMS-R Visual Paired Associates (immediate) & 1239 & $9.1(3.8)$ & $8.9(3.8)$ & $9.3(3.8)$ & 0.08 \\
\hline WMS-R Visual Paired Associates (delayed) & 1237 & $3.4(1.8)$ & $3.3(1.8)$ & $3.4(1.8)$ & 0.38 \\
\hline \multicolumn{6}{|l|}{ Executive function } \\
\hline CERAD Category Fluency & 1257 & $21.6(5.7)$ & $21.3(5.6)$ & $21.8(5.8)$ & 0.13 \\
\hline WMS-R Digit Span (total) & 1258 & $11.5(2.9)$ & $11.5(2.9)$ & $11.4(2.9)$ & 0.64 \\
\hline CST $($ condition $\mathrm{C}) *$ & 1157 & $65.2(40.6)$ & $64.3(37.2)$ & $66.1(43.7)$ & 0.44 \\
\hline TMT shifting score $(\mathrm{B}-\mathrm{A}) *$ & 1180 & $107.7(65.7)$ & $110.8(66.9)$ & $104.6(64.4)$ & 0.10 \\
\hline Stroop test interference score $(3-2) *$ & 1240 & $34.6(18.0)$ & $34.8(18.1)$ & $34.4(17.8)$ & 0.69 \\
\hline \multicolumn{6}{|l|}{ Processing speed } \\
\hline Letter Digit Substitution Test & 1253 & $22.0(6.0)$ & $21.7(5.9)$ & $22.2(6.0)$ & 0.14 \\
\hline CST $($ condition A) * & 1256 & $33.1(9.5)$ & $33.3(8.9)$ & $32.8(10.0)$ & 0.33 \\
\hline Stroop test (condition 2) $*$ & 1251 & $29.5(6.4)$ & $29.6(6.3)$ & $29.3(6.5)$ & 0.55 \\
\hline Mini Mental State Examination & 1257 & $26.7(2.0)$ & $26.7(2.0)$ & $26.8(2.0)$ & 0.55 \\
\hline
\end{tabular}

\subsection{Discussion}

The FINGER study is one of the first large multidomain intervention studies aiming at preventing cognitive impairment and dementia. Participants were recruited from earlier non-intervention population-based surveys in Finland, which gives unique background information about the target population typically not available in clinical trials. Analysing these data indicates that persons who did not attend the screening visit of the FINGER study were older, more often men, less educated and had more vascular and lifestyle related risk factors compared to those who were screened. However, baseline clinical characteristics of the participants indicate that several vascular risk factors and unhealthy lifestyle related factors were present, creating a window of opportunity for prevention. The intervention and control groups were similar at the beginning of the trial indicating that the randomization worked well.

Our results are in line with previous epidemiological studies on dementia/AD showing that participants are in general younger, more educated, and healthier than non-participants [9-11]. 
However, very little has been known about participation in prevention trials targeting lifestyle related risk factors among elderly persons. Because the FINGER study includes a long-term and relatively intensive multidomain intervention, it was expected that older persons with worse health status were less likely to participate. To balance the healthy volunteer bias that is often present especially in studies using advertisement, we used the CAIDE Dementia Risk score as one inclusion criteria. We used the cut-off of 6 points or more in the CAIDE risk score to select persons with some modifiable risk factors [15,19]. A large proportion (more than $80 \%$ ) of the target-aged population met these criteria based on the data from the earlier population-based surveys, and only those with a very low risk of dementia were excluded.

The FINGER population was defined in relation to the goals of the trial and was not intended to be representative of the general population. Nevertheless, the levels of several risk factors in our randomized participants were quite similar to those observed in the general population of the same age: for example in the National FINRISK study in 2012 [29], mean serum total cholesterol level in the Finnish population aged 65-74 years was 5.6 in women and $5.0 \mathrm{mmol} / \mathrm{L}$ in men, mean body mass index 28.0 and $28.3 \mathrm{~kg} / \mathrm{m}^{2}$, and mean systolic blood pressure 146 and $144 \mathrm{mmHg}$, respectively. However, the proportion of persons with self-reported hypertension and hypercholesterolemia was higher and the proportion of those with regular physical activity was lower in our study population than in the general population of the same age. This is in line with the fact that the CAIDE Dementia Risk Score including the previously mentioned factors was used in recruiting the participants of the FINGER study.

Our inclusion criteria for cognition at the screening visit were used in order to select a high-risk population, and to exclude both the individuals whose cognitive performance was above the mean level for their age and those with substantial cognitive impairment or dementia. While the main reason for non-eligibility was too good cognitive performance, the group of non-randomized persons was still heterogeneous and included also persons with too low cognitive performance, severe diseases or otherwise unable/willing to participate to the trial. As the CAIDE risk score emphasizes vascular risk factors and the cognitive inclusion criteria is memory-related, in theory our study population is at risk of both AD type and vascular cognitive impairment. The mean cognitive performance of our study population was less than $0.5 \mathrm{SD}$ below the average level of a cognitively normal Finnish population. The neuropsychological test battery that was used in the FINGER study includes a set of widely used standard tests, and it is a modified version of test battery that was previously shown to be sensitive to cognitive changes in persons with mild AD [23]. We added standard tests measuring attention and executive functions to the original test battery, in order to better capture also changes typical in vascular cognitive impairment.

In order to have high external validity, i.e., that our results would be as generalizable as possible, we kept the exclusion criteria to the minimum and used six study areas that provided good geographical coverage within Finland and comprised both urban and rural areas. The participants were invited from earlier population-based surveys that had very good participation rates and therefore can be considered well representative of the Finnish population. Although we have important information of the characteristics of the screening visit non-attendees, we do not know why they chose not to attend. Both the nature of the trial and characteristics (such as age or health status) of the target population may have played a role. It remains a task for the future to identify if there is something we 
could do to facilitate participation in future trials and/or when implementing preventive strategies into practice. The differences between the screening visit attendees and non-attendees will not compromise the expected results of our trial, but they are important to identify in order to understand to what extent our results may be generalizable to the population at-large. We hypothesize that the persons with more risk factors would benefit more from the intervention, so given the fact that the study participants had somewhat less risk factors present may underestimate the effect of the intervention in the whole target population.

The FINGER study is using an existing infrastructure and a research framework built for cardiovascular risk factor monitoring to recruit a population that would benefit most from the intervention. Detailed information on earlier lifestyle and vascular factors is available, and differences in these variables can be taken into account in the analyses, which is usually not possible in randomized controlled trials. An extended follow-up of the cohort after the end of the 2 year intervention will provide much needed information on the long-term effects of the 2-year intervention, especially on the incidence of dementia/AD. We will utilize the exceptional opportunities available in Finland, including structured and detailed health registers of high quality, to ensure a complete long-term follow-up on a wide range of outcomes also for the persons who did not participate in the screening or the actual trial, were not included or dropped out during the study.

\section{Conclusions}

Vascular risk factors were more common among those who did not attend the FINGER study screening visit than among those who attended. Nevertheless, as expected from the inclusion criteria the participants had several modifiable risk factors for dementia and cognitive impairment at baseline indicating a window of opportunity for the intervention. The random allocation of participants to the intervention and control groups was successful. The FINGER study is expected to provide important novel information on the effect of lifestyle intervention to prevent cognitive impairment among at risk persons selected from the general population.

\section{Acknowledgments}

The authors thank all participants in the FINGER study and members of the FINGER study group for their cooperation and data collection and management. This study was supported by Academy of Finland's Responding to Public Health Challenges Research Programme (SALVE) grants 129395, 129397, 129459, 129421, 129416, 129511, 129401, 259615, La Carita Foundation, Alzheimer Association grant (HAT-10-173121), Alzheimer's Research and Prevention Foundation, Juho Vainio Foundation, Novo Nordisk Foundation, Finnish Social Insurance Institution, and EVO grants of local hospitals, as well as personal grants from Academy of Finland 120676 and 11745 (Miia Kivipelto), 251645 (Alina Solomon), Swedish Society for Medical Research (Tiia Ngandu), and Saastamoinen foundation (Alina Solomon). The blood pressure monitoring devices were provided by Microlife.

FINGER Study Group: Main investigator: Miia Kivipelto; Coordination: Satu Ahtiluoto, Tiia Ngandu, Jenni Lehtisalo; Sub-cohort leaders: Miia Kivipelto (Helsinki cohort), Tiina Laatikainen (Vantaa cohort), Hilkka Soininen (Kuopio cohort), Timo Strandberg (Oulu cohort), Antti Jula (Turku cohort), Jaakko Tuomilehto (Seinäjoki cohort); Statistical analyses: Markku Peltonen and 
Esko Levälahti; Intervention supervision: Jaana Lindström, and Jenni Lehtisalo (nutrition component), Rainer Rauramaa and Satu Pajala (physical exercise component), Tuomo Hänninen and Tiia Ngandu (cognitive component), Timo Strandberg, Riitta Antikainen, and Jaakko Tuomilehto (vascular risk factor component). The cognitive component was designed in collaboration with Lars Bäckman and Anna Stigsdotter-Neely. Other study members and collaborators: Raimo Sulkava, Alina Solomon, Teemu Paajanen, Marko Grönholm, Liisa Saarikoski, Francesca Mangialasche, Juha Rinne.

\section{Author Contributions}

Tiia Ngandu and Miia Kivipelto contributed to the study conception and design. Tiia Ngandu, Jenni Lehtisalo, Satu Ahtiluoto, Tiina Laatikainen, Jaana Lindström, Markku Peltonen, Riitta Antikainen, Tuomo Hänninen, Satu Pajala, Rainer Rauramaa, Timo Strandberg, Jaakko Tuomilehto, Hilkka Soininen, and Miia Kivipelto were involved in planning the FINGER study protocol. Tiia Ngandu, Jenni Lehtisalo and Satu Ahtiluoto were involved in the baseline survey data collection. Esko Levälahti and Tiia Ngandu analysed the data. Tiia Ngandu and Miia Kivipelto drafted the manuscript. All authors critically revised the manuscript for important intellectual content. Tiina Laatikainen, Rainer Rauramaa, Timo Strandberg, Jaakko Tuomilehto, Hilkka Soininen and Miia Kivipelto obtained funding for the study. Miia Kivipelto is the principal investigator of the FINGER study.

\section{Conflicts of Interest}

The authors declare no conflict of interest.

\section{References}

1. Prince, M.; Bryce, R.; Albanese, E.; Wimo, A.; Ribeiro, W.; Ferri, C.P. The global prevalence of dementia: A systematic review and metaanalysis. Alzheimers Dement. 2013, 9, 63-75.

2. Mangialasche, F.; Kivipelto, M.; Solomon, A.; Fratiglioni, L. Dementia prevention: Current epidemiological evidence and future perspective. Alzheimers Res. Ther. 2012, 4, doi:10.1186/alzrt104.

3. Williams, J.; Plassman, B.; Burke, J.; Holsinger, T.; Benjamin, S. Preventing Alzheimer's Disease and Cognitive Decline; Evidence Report/Technology Assessment No. 193; Agency for Healthcare Research and Quality: Rockville, MD, USA, 2010.

4. Peters, R.; Beckett, N.; Forette, F.; Tuomilehto, J.; Clarke, R.; Ritchie, C.; Waldman, A.; Walton, I.; Poulter, R.; Ma, S.; et al. Incident dementia and blood pressure lowering in the Hypertension in the Very Elderly Trial cognitive function assessment (HYVET-COG): A double-blind, placebo controlled trial. Lancet Neurol. 2008, 7, 683-689.

5. De Jager, C.A.; Oulhaj, A.; Jacoby, R.; Refsum, H.; Smith, A.D. Cognitive and clinical outcomes of homocysteine-lowering B-vitamin treatment in mild cognitive impairment: A randomized controlled trial. Int. J. Geriatr. Psychiatry 2012, 27, 592-600.

6. Lautenschlager, N.T.; Cox, K.L.; Flicker, L.; Foster, J.K.; van Bockxmeer, F.M.; Xiao, J.; Greenop, K.R.; Almeida, O.P. Effect of physical activity on cognitive function in older adults at risk for Alzheimer disease: A randomized trial. JAMA 2008, 300, 1027-1037. 
7. Willis, S.L.; Tennstedt, S.L.; Marsiske, M.; Ball, K.; Elias, J.; Koepke, K.M.; Morris, J.N.; Rebok, G.W.; Unverzagt, F.W.; Stoddard, A.M.; et al. Long-term effects of cognitive training on everyday functional outcomes in older adults. JAMA 2006, 296, 2805-2814.

8. Tuomilehto, J.; Lindstrom, J.; Eriksson, J.G.; Valle, T.T.; Hamalainen, H.; Ilanne-Parikka, P.; Keinanen-Kiukaanniemi, S.; Laakso, M.; Louheranta, A.; Rastas, M.; et al. Prevention of type 2 diabetes mellitus by changes in lifestyle among subjects with impaired glucose tolerance. N. Engl. J. Med. 2001, 344, 1343-1350.

9. Prindle, J.J.; McArdle, J.J. How representative is the ACTIVE sample? A statistical comparison of the ACTIVE sample and the HRS sample. J. Aging Health 2014, 25, 85S-102S.

10. Launer, L.J.; Wind, A.W.; Deeg, D.J. Nonresponse pattern and bias in a community-based cross-sectional study of cognitive functioning among the elderly. Am. J. Epidemiol. 1994, 139, 803-812.

11. Rusanen, M.; Ngandu, T.; Laatikainen, T.; Tuomilehto, J.; Soininen, H.; Kivipelto, M. Chronic obstructive pulmonary disease and asthma and the risk of mild cognitive impairment and dementia: A population based CAIDE study. Curr. Alzheimer Res. 2013, 10, 549-555.

12. Harris, T.J.; Victor, C.R.; Carey, I.M.; Adams, R.; Cook, D.G. Less healthy, but more active: Opposing selection biases when recruiting older people to a physical activity study through primary care. BMC Public Health 2008, 8, 182, doi:10.1186/1471-2458-8-182.

13. Van Heuvelen, M.J.; Hochstenbach, J.B.; Brouwer, W.H.; de Greef, M.H.; Zijlstra, G.A.; van Jaarsveld, E.; Kempen, G.I.; van Sonderen, E.; Ormel, J.; Mulder, T. Differences between participants and non-participants in an RCT on physical activity and psychological interventions for older persons. Aging Clin. Exp. Res. 2005, 17, 236-245.

14. Ives, D.G.; Traven, N.D.; Kuller, L.H.; Schulz, R. Selection bias and nonresponse to health promotion in older adults. Epidemiology 1994, 5, 456-461.

15. Kivipelto, M.; Solomon, A.; Ahtiluoto, S.; Ngandu, T.; Lehtisalo, J.; Antikainen, R.; Backman, L.; Hanninen, T.; Jula, A.; Laatikainen, T.; et al. The finnish geriatric intervention study to prevent cognitive impairment and disability (FINGER): Study design and progress. Alzheimers Dement. 2013, 9, 657-665.

16. Vartiainen, E.; Laatikainen, T.; Peltonen, M.; Juolevi, A.; Mannisto, S.; Sundvall, J.; Jousilahti, P.; Salomaa, V.; Valsta, L.; Puska, P. Thirty-five-year trends in cardiovascular risk factors in Finland. Int. J. Epidemiol. 2010, 39, 504-518.

17. Saaristo, T.; Peltonen, M.; Keinanen-Kiukaanniemi, S.; Vanhala, M.; Saltevo, J.; Niskanen, L.; Oksa, H.; Korpi-Hyovalti, E.; Tuomilehto, J. National type 2 diabetes prevention programme in Finland: FIN-D2D. Int. J. Circumpolar Health 2007, 66, 101-112.

18. Peltonen, M.; Harald, K.; Männistö, S.; Saaikoski, S.; Peltomäki, P.; Lund, L.; Sundvall, J.; Juolevi, A.; Laatikainen, T.; Aldén-Nieminen, H.; et al. Kansallinen FINRISKI 2007-Terveystutkimus —Tutkimuksen Toteutus ja Tulokset; Kansanterveyslaitoksen Julkaisuja B34/2008; KTL-National Public Health Institute: Helsinki, Finland, 2008.

19. Kivipelto, M.; Ngandu, T.; Laatikainen, T.; Winblad, B.; Soininen, H.; Tuomilehto, J. Risk score for the prediction of dementia risk in 20 years among middle aged people: A longitudinal, population-based study. Lancet Neurol. 2006, 5, 735-741. 
20. Morris, J.C.; Heyman, A.; Mohs, R.C.; Hughes, J.P.; van Belle, G.; Fillenbaum, G.; Mellits, E.D.; Clark, C. The Consortium to Establish a Registry for Alzheimer's Disease (CERAD). Part I. Clinical and neuropsychological assessment of Alzheimer's disease. Neurology 1989, 39, 1159-1165.

21. Pulliainen, V.; Hänninen, T.; Hokkanen, L.; Tervo, S.; Vanhanen, M.; Pirttilä, T.; Soininen, H. Norms for use of the CERAD test battery in Finland. Suom. Lääkäril. (Finn. Med. J.) 2007, 62, 1235-1241.

22. Guralnik, J.M.; Simonsick, E.M.; Ferrucci, L.; Glynn, R.J.; Berkman, L.F.; Blazer, D.G.; Scherr, P.A.; Wallace, R.B. A short physical performance battery assessing lower extremity function: Association with self-reported disability and prediction of mortality and nursing home admission. J. Gerontol. 1994, 49, M85-M94.

23. Harrison, J.; Minassian, S.L.; Jenkins, L.; Black, R.S.; Koller, M.; Grundman, M. A neuropsychological test battery for use in Alzheimer disease clinical trials. Arch. Neurol. 2007, 64, 1323-1329.

24. Wechsler, D. WMS-III-Administration and Scoring Manual; Psychological Corporation Ltd.: London, UK, 1998.

25. Van der Elst, W.; Van Boxtel, M.P.; Van Breukelen, G.J.; Jolles, J. The concept shifting test: Adult normative data. Psychol. Assess. 2006, 18, 424-432.

26. Reitan, R.M. Validity of the trail making test as an indicator of organic brain damage. Percept. Mot. Skills 1958, 8, 271-276.

27. Golden, C. Stroop Color and Word Test: A Manual for Clinical and Experimental Uses; Skoelting: Chicago, IL, USA, 1978.

28. Van der Elst, W.; van Boxtel, M.P.; van Breukelen, G.J.; Jolles, J. The letter digit substitution test: Normative data for 1858 healthy participants aged 24-81 from the Maastricht Aging Study (MAAS): Influence of age, education, and sex. J. Clin. Exp. Neuropsychol. 2006, 28, 998-1009.

29. Borodulin, K.; Levälahti, E.; Saarikoski, L.; Lund, L.; Juolevi, A.; Grönholm, M.; Jula, A.; Laatikainen, T.; Männistö, S.; Peltonen, M.; et al. Kansallinen FINRISKI 2012Terveystutkimus-Osa 2: Tutkimuksen taulukkoliite. Terveyden ja Hyvinvoinnin Laitos; Raportti 2013/22_Osa_ii; Juvenes Print_-Suomen Yliopistopaino Oy: Tampere, Finland, 2013.

(C) 2014 by the authors; licensee MDPI, Basel, Switzerland. This article is an open access article distributed under the terms and conditions of the Creative Commons Attribution license (http://creativecommons.org/licenses/by/3.0/). 